\title{
Práticas do Supervisor Acadêmico na Formação do Psicólogo: Estudo Bibliométrico
}

Academic Supervisor Practices in Psychologist Education: Bibliometric Study

Prácticas del Supervisor Académico en la Formación del Psicólogo: Estudio Bibliométrico

Walter Mariano de Faria Silva Neto

Universidade Federal do

Triângulo Mineiro

Wanderlei Abadio de Oliveira

Universidade de São Paulo

http://dx.doi.org/ 10.1590/1982-3703001632014

(cc) BY 
Resumo: Objetivou-se conhecer e mapear a produção científica sobre práticas e experiências de supervisores de estágio acadêmico na formação em Psicologia no Brasil. A estratégia de busca eletrônica foi realizada em três bases de dados (IndexPsi, Pepsic e SciElo). Também foram consultadas as listas de referência dos artigos identificados. Os termos-chave usados na busca foram supervisão e psicologia. A busca selecionou 22 artigos, publicados entre 1970 e 2012, que foram analisados segundo seus indicadores bibliométricos e de acordo com o foco desta revisão. Verificou-se que a supervisão acadêmica é um momento importante da formação do psicólogo no qual o supervisor exerce papel central quanto à construção da identidade profissional dos estudantes. Existem lacunas relativas à reflexão sobre as práticas de supervisão e suas diferentes variáveis. Outras pesquisas são estimuladas para abordar os espaços de supervisão e as trajetórias dos supervisores no exercício dessa função.

Palavras-chave: Supervisão acadêmica. Supervisão prática. Psicologia. Bibliometria.

\begin{abstract}
This study aimed to identify and map scientific literature on the practices and experiences of supervisors of academic internships in Brazilian psychology education. The electronic search strategy focused on three databases: IndexPsi, Pepsic, and SciElo. The reference lists in articles were also considered as sources as well. Supervision and psychology were the key terms used in the search, which resulted in 22 articles being published between 1970 and 2012. Articles were analyzed according to both their bibliometric indicators and this review's focus. Results show that academic supervision is an important period of the training of a psychologist and that the supervisor plays a central role in the formation of students' professional identity. However, there remain gaps in the study of supervisory practices and their different variables. Further research is encouraged to address supervision spaces and supervisors' background in performing their role.
\end{abstract}

Keywords: Academic supervision. Practice supervision. Psychology. Bibliometrics.

Resumen:Este estudio tuvo como objetivo comprender y mapear la literatura científica sobre las prácticas y experiencias de supervisores de pasantías académicas en la formación de psicología en Brasil. La estrategia de búsqueda electrónica se realizó en tres bases de datos (IndexPsi, Pepsic y SciELO). También se consultaron las listas de referencias de los artículos identificados. En la búsqueda fueron utilizadas dos palabras claves: supervisión y psicología. La búsqueda seleccionó 22 artículos publicados entre 1970 y 2012, analizados de acuerdo con sus indicadores bibliométricos y el enfoque de esta revisión. Los resultados muestran que la supervisión académica es un momento importante en la formación del psicólogo donde el supervisor ejerce un papel central en la construcción de la identidad profesional de los estudiantes. Existen lagunas relacionadas con la reflexión sobre las prácticas de supervisión y sus diferentes variables. Otras investigaciones son estimuladas para abordar los espacios de supervisión y las trayectorias de los supervisores en el ejercicio de esta función.

Palabras clave: Supervisión académica. Supervisión práctica. Psicología. Bibliometría.

\section{Introdução}

A supervisão de estágio na formação do psicólogo é um território educativo que congrega as experiências dos estudantes estagiários e as questões institucionais, além do fazer e dos saberes dos supervisores. Esse momento oportuniza a identificação, o ensino e o manejo inicial de elementos que compõem a técnica e prática profissional. Na graduação em Psicologia, a supervisão é obrigatória e se caracteriza pela tutela dos alunos em sua imersão na prática profissional, de modo que possam experimentar situações que suscitem reflexão sobre a prática profissional, a formação e as relações estabelecidas no âmbito da supervisão. 
Este estudo sobre o processo de supervisão do futuro psicólogo permite discutir o quão alienante ou conscientizador tem sido tal processo e o quão contributivo pode ser à compreensão da atividade do psicólogo/supervisor em contextos formativos. A perspectiva adotada - conhecer as publicações nacionais sobre o tema - busca estimular investimentos na reflexão sobre a formação em Psicologia, em especial o momento dos estágios e o processo de supervisão, e sobre a figura do supervisor e suas práticas.

Como processo essencial na formação profissional do psicólogo, a supervisão tem momentos históricos de regulamentação da profissão e do debate sobre o tema no Sistema Conselhos de Psicologia. No campo da produção científica, há uma variedade no uso dos termos mais gerais, como o termo supervisão, que, relacionado com a formação acadêmica, é usado em duas áreas principais: uma vinculada à supervisão pedagógica na formação de professores; outra relativa à formação densa dos profissionais da saúde. Também é expressiva a produção acerca da supervisão na formação em psicanálise (Silva Neto, 2014).

Na educação, a prática de supervisionar no processo de formação de professores possibilita não só reflexões críticas, mas também a construção da identidade profissional e das características da função do educador no processo de ensino e aprendizagem (Andrade, 2005). Noutra direção - da unidade entre teoria e prática do estágio no âmbito do serviço social -, um estudo buscou refletir sobre a importância desse momento potencializador para o exercício do futuro cotidiano profissional, abordando também o papel fundamental que a supervisão de estágio assume no chamado processo didático-pedagógico de formação profissional (Assis \& Rosado, 2012). A presença de artigos sobre supervisão em psicanálise se relaciona com as características específicas desse tipo de formação/atuação profissional, alicerçada em três pilares: análise didática, seminários teóricos e supervisão clínica de análises (Zaslavsky, Nunes \& Eizirik, 2003).
São encontrados na literatura artigos sobre relatos de experiência de estagiários e supervisores com foco nas atividades desenvolvidas nos campos e nas áreas de estágio. Verificaram-se produções que apresentam e/ou relatam as experiências e questões nelas suscitadas (Delvan, Ramos, \& Dias, 2002; Emílio, Mataresi, Horvat \& Figueiredo, 2012; Ulup \& Barbosa, 2012). Em geral, o enfoque incide no papel do estágio na formação, com suas perspectivas teóricas e as estratégias utilizadas no âmbito da prática (Delvan et al., 2002). Esse tipo de abordagem, focalizada nos relatos de experiências em estágios, tem sido frequente em periódicos distintos e é importante para uma reflexão sobre o processo de formação - sobre como tem ocorrido em contextos variados do Brasil - e acerca da forma como se desenvolvem as atividades nas chamadas clínicas-escolas.

A regulamentação da atividade de supervisão, especificamente, aparece no campo das diretrizes para a formação do psicólogo. Como processo, vincula-se ao estágio, concebido como momento que facilita o exercício profissional futuro e o treinamento prático dos estudantes. Os estágios ocorrem em áreas diversas da Psicologia e exigem competências do supervisor para administrar as técnicas e orientações pertinentes a cada uma. Assim, o exercício do estagiário e a atividade do supervisor acadêmico integram o terreno da orientação e a construção de novas práticas profissionais, mediadas pela experiência do psicólogo supervisor e enquadradas nas legislações específicas da Psicologia e da lei de estágio para essa dimensão da formação no ensino superior (Costa Júnior \& Holanda, 1996).

É nesse cenário que se delineia o papel do supervisor acadêmico: responsável pelo acompanhamento e pela avaliação das atividades desenvolvidas pelos estagiários para garantir a integração do eixo teórico-prático e o desenvolvimento de competências para o futuro exercício profissional. Sua prática deve se configurar como não tutelada, de modo a estimular o desenvolvimento da autonomia do psicólogo em formação e a reflexão crítica do exercício da Psicologia fundada no contexto 
social e institucional (quanto aos campos de estágio) em que se insere (Barletta, Fonsêca, \& Delabrida, 2012; Sakamoto, 2006; Silva, Ribeiro, \& Marçal, 2004).

Percebe-se que questões relativas à legislação da supervisão estão atreladas às legislações e normatizações da prática do estágio acadêmico, tanto quanto a dimensões como o registro de trabalho do professor do ensino superior e os mecanismos institucionais. Tais dimensões tendem a repercutir na prática e na maneira como esses profissionais percebem, sentem e constroem esse fazer, pois ser supervisor é uma das potencialidades do exercício profissional do psicólogo articulada a conhecimentos acadêmicos (Costa Júnior \& Holanda, 1996; Dias, 1998; Sakamoto, 2006).

Dada essa relevância da supervisão acadêmica para o processo formativo do psicólogo, este estudo bibliométrico fortalece a discussão sobre as práticas dos supervisores divulgadas na literatura científica. Seu objetivo central foi conhecer e mapear a produção científica sobre práticas e experiências de supervisores de estágio acadêmico na formação em Psicologia no Brasil. Buscou-se evidenciar o número e o perfil dos artigos publicados, identificando as tendências, as áreas principais de divulgação e as perspectivas adotadas.

\section{Método}

A pesquisa subjacente a este texto constitui uma revisão bibliométrica da literatura feita mediante a busca especializada de estudos publicados em periódicos indexados. Os procedimentos da revisão ocorreram entre janeiro e junho de 2014. As fontes de consulta incluem bases de dados eletrônicas e uma biblioteca de uma universidade pública do interior de São Paulo. Estudos dessa natureza permitem analisar a produção científica sobre determinados temas e intervenções, propiciando a construção de indicadores e parâmetros confiáveis para avaliar e reformular práticas e saberes. Preambularmente, foram definidos o objetivo e a questão científica norteadora da proposta de revisão, qual seja: como as práticas de supervisão de estágio acadêmico na formação em Psicologia no
Brasil são apresentadas na literatura científica? A população de interesse foram os psicólogos supervisores, tendo como foco a supervisão acadêmica, circunscrita às graduações em Psicologia.

A estratégia de busca se desenvolveu nas bases de dados IndexPsi, Pepsic e SciElo. Além disso, foi consultada a lista de referências dos artigos identificados nas bases a fim de reconhecer estudos relevantes não identificados pela estratégia de busca. Cabe frisar que estratégias diversificadas na execução da revisão garantem que a sondagem em busca de evidências científicas seja mais eficiente, isto é, maximize a identificação de textos úteis à abordagem dos temas investigados. As palavras-chave supervisão e psicologia foram empregadas de forma livre numa busca simples nas bases. O cruzamento desses dois termos garantiu a identificação e inclusão de todos os artigos que enfocam o tema investigado. Ponderou-se que a inclusão de outros termos poderia limitar excessivamente a busca ou aumentar o risco de viés e perda.

Os critérios para a seleção dos estudos foram o idioma - português; a independência do ano de publicação; a exposição, os relatos ou as análises de práticas de supervisores acadêmicos de Psicologia; e as publicações com delineamentos metodológicos distintos. Dissertações, teses, notas e cartas editoriais foram preteridas ao artigo científico como fonte de informação. Dados o objetivo e a questão norteadora deste estudo de revisão, o idioma português foi escolhido porque não se justificariam estudos em outro idioma, ou seja, originários de outros contextos socioculturais.

Definidos esses aspectos estratégicos, veio a etapa de buscas. Num primeiro momento, todos os achados possíveis foram considerados; depois ocorreu o primeiro refinamento por meio da leitura e análise de títulos e resumos. Como etapa seguinte, houve a localização dos artigos na íntegra nas bases de dados ou na biblioteca universitária quando os textos não estavam indexados. A Figura sumariza a seleção dos textos que compõem o corpus desta revisão. 


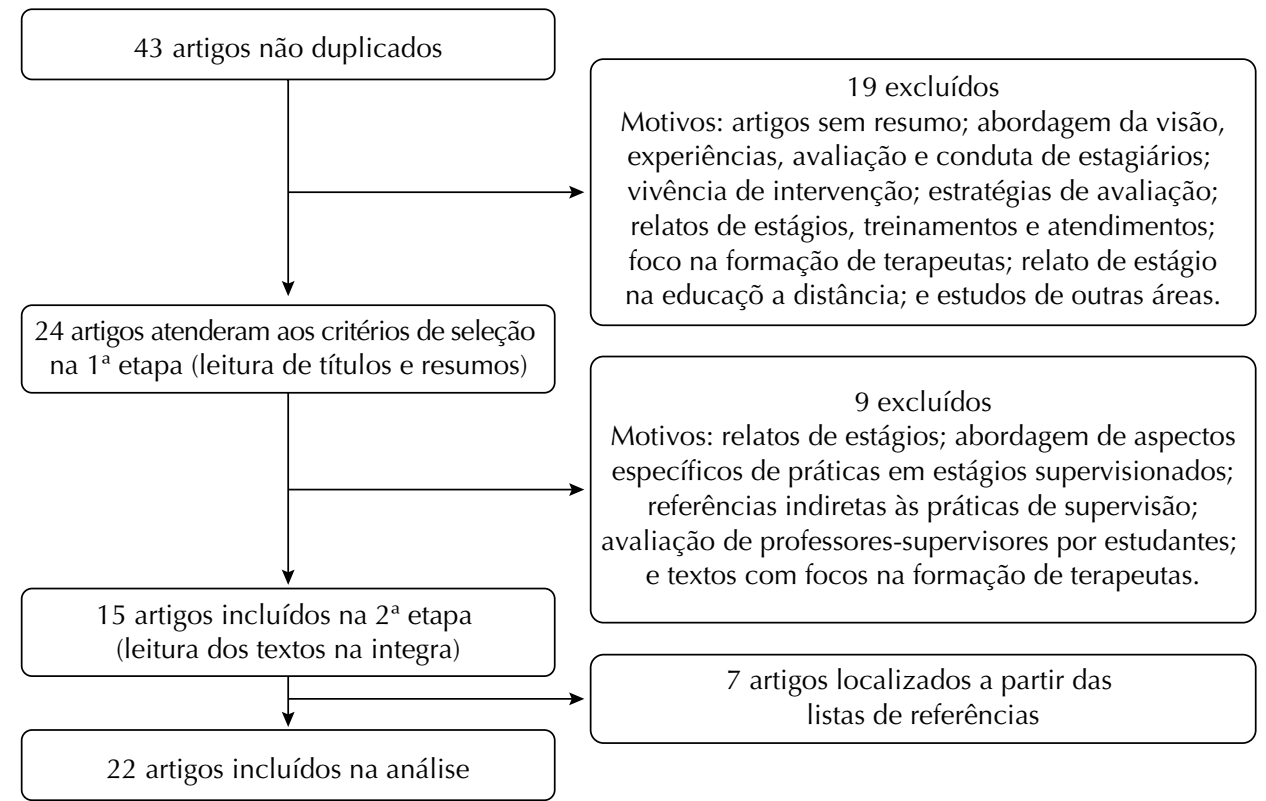

Fonte: Dados da pesquisa.

Figura. Fluxograma do processo de seleção do corpus revisado

A aplicação dos critérios mencionados na seleção justificou a exclusão de 28 estudos nesta revisão. Os indicadores bibliométricos usados na organização dos estudos selecionados incluem ano de publicação, título, tema, palavras-chave, foco do estudo, área da Psicologia, periódico, sujeitos, tipo de pesquisa e referencial teórico de fundamentação. Esses indicadores foram organizados em um quadro sinóptico para auxiliar, de forma complementar, a análise descritiva das publicações elegíveis $(n=22)$. A avaliação crítica dos estudos incluídos na revisão foi sumarizada, e as principais informações dos resultados dos artigos foram sintetizadas a fim de que permitissem verificar a frequência das áreas e os temas mais significativos e explorados.

\section{Resultados e discussão}

O exercício desta revisão demonstrou variedade e polissemia significativas no uso do vocábulo supervisão quando relacionado com a formação acadêmica. Verificou-se uma presença marcante da temática do estágio acadêmico ou supervisionado nos cursos de Psicologia, com publicação expressiva de relatos de experiência. Além disso, a temática tem sido muito explorada por outras áreas de formação, tais como a saúde e a educação, prioritariamente, bem como na supervisão da formação em psicanálise.

Para o foco desta revisão, foram analisados 22 artigos, dos quais 15 foram incluídos na consulta às bases de dados, enquanto sete foram identificados na lista de referências dos 15 textos. A Tabela 1 apresenta o panorama dos artigos revisados segundo seus indicadores bibliométricos.

Quanto à produtividade segundo o ano de publicação, em 2006 houve o maior número de publicações $(n=5)$, seguido pelo ano de $2011(n=3)$. Esses dados permitem inferir que o tema é transversal e presente na história da Psicologia como profissão no Brasil, pois, dos textos identificados, o mais antigo data de 1970. A distribuição do número de artigos publicados em mais de quatro décadas - cabe frisar - é pequena e não pode ser considerada como expressiva ou representativa em razão da complexidade e importância da supervisão para a formação do psicólogo brasileiro. 
Tabela 1. Distribuição dos estudos revisados segundo indicadores bibliométricos

\begin{tabular}{ll}
\hline Indicadores bibliométricos & $\mathbf{N}^{\mathbf{o}}$ de art \\
\hline Ano de publicação & 1 \\
1970 & 1 \\
1995 & 1 \\
1996 & 2 \\
1998 & 1 \\
1999 & 1 \\
2002 & 1 \\
2003 & 2 \\
2004 & 5 \\
2006 & 1 \\
2009 & 2 \\
2010 & 3 \\
2011 & 1 \\
2012 & 1
\end{tabular}

Revista

Psicologia: Ciência e Profissão 3

Psicologia em Estudo (Maringá) 3

Ágora 1

Aletheia 1

Arquivos Brasileiros de Psicologia

Cadernos de Psicopedagogia $\quad 1$

Estudos de Psicologia Campinas $\quad 1$

Estudos e Pesquisas em Psicologia

Revista de Psicologia, da Vetor editora $\quad 1$

Psicologia da América Latina $\quad 1$

Psicologia Clínica 1

Psicologia Escolar e Educacional $\quad 1$

Psicologia: Ensino e Formação

Psicologia: Teoria e Prática 1

Revista Abordagem Gestalt

Revista Brasileira de Terapias Cognitivas $\quad 1$

Revista da ABOP 1

Temas em Psicologia $\quad 1$

Tipo de estudo

$\begin{array}{ll}\text { Relato de experiência } & 10\end{array}$

Ensaio reflexivo $\quad 8$

Pesquisa de campo $\quad 4$ 
Tabela 1. Continuação

\begin{tabular}{lr}
\hline Foco dos estudos & 10 \\
O espaço da supervisão & 5 \\
Estágio supervisionado ou acadêmico & 3 \\
Formação de psicólogos & 2 \\
Estagiários de Psicologia & 2 \\
Supervisores de estágio acadêmico & 22 \\
\hline Total de artigos
\end{tabular}

Fonte: Dados da pesquisa.

As revistas Psicologia: Ciência e Profissão e Psicologia em Estudo publicaram a maioria dos artigos lidos para esta revisão $(n=6)$. Talvez porque o escopo e a linha editorial desses periódicos, respectivamente, abrem-se sobremaneira, a questões da formação profissional do psicólogo e, do ponto de vista metodológico, priorizem artigos de delineamento qualitativo, o que também se relaciona ao tipo de desenho metodológico dos textos. No conjunto, ainda se observou que o tema ficou circunscrito a edições da Psicologia ou de temáticas a ela concernentes, com um texto publicado em uma revista de psicopedagogia.

Dentre os principais focos dos artigos, o espaço da supervisão foi o mais abordado $(n=10)$, seguido pelo estágio supervisionado ou acadêmico em si $(n=5)$. Esse dado remonta ao momento da formação do psicólogo, em que se inserem a supervisão e o estágio. Os estudos são coerentes ao enfatizarem que, na prática, a supervisão é um espaço para a aprendizagem de manejos técnicos da Psicologia, que são influenciados sobremaneira pela abordagem teórica dos anos iniciais de formação. Noutros termos, desenvolve-se uma reflexão sobre a supervisão acadêmica sem se considerar a experiência prática em que os estagiários estarão imersos nem a formação teórica para esse momento. A Tabela 2 sumariza elementos de análise sobre questões teóricas e de abordagem dos artigos revisados.

Percebe-se que o foco da maior parte das pesquisas é na supervisão clínica $(n=13)$, no saber e no fazer clínico do psicólogo. Reconhecida como um exercício profissional do psicólogo dos mais tradicionais e frequentes, a prática clínica se destaca na divulgação científica sobre como ocorre a formação com este fim. Entretanto, outras áreas também constituem cenários importantes da prática do psicólogo e já divulgam experiências de formação que abordam aspectos gerais desta ou de áreas específicas como a Psicologia Escolar ou de orientação profissional. Nessa mesma direção, foi significativo o aparecimento de abordagens clínicas nos estudos revisados. Reconhece-se que, assim como o estágio ocorrerá em dada perspectiva, as práticas de supervisão farão o mesmo.

Um item se destacou: a falta de clareza ou definição do referencial teórico de alguns estudos $(n=6)$. A Psicologia tem um conjunto teórico amplo que poderia contribuir para as análises desenvolvidas pelos autores, além de problematizar suas questões de pesquisa segundo pontos específicos ebem delineados. Também se sobressaiu a multiplicidade de palavras-chave usadas na indexação dos artigos como problemática identificada nessa revisão. No âmbito da produção científica, essa multiplicidade expõe a abrangência do assunto e seus conceitos principais, mas pode complicar a identificação ou categorização dos textos. A realização desta revisão indicou que localizar artigos sobre a temática abordada requer uso de poucas variações de termos nos procedimentos de busca, dadas essas características de indexação; caso contrário, o pesquisador pode deixar de encontrar textos relevantes para seu estudo, seja de revisão como este ou para subsidiar pesquisas e discussões de dados empíricos. 
Tabela 2. Distribuição dos estudos revisados segundo a área da Psicologia, o referencial teórico e as palavras-chave

\section{Elementos de análise}

$\mathbf{N}^{\circ}$ de ocorrência

Área temática dos artigos

Psicologia Clínica (diferentes abordagens)

Formação do psicólogo

Psicologia Escolar

Orientação profissional

Psicologia Hospitalar

Psicologia Jurídica

Psicologia Social

Referencial teórico dos artigos

Psicanálise

Psicologia Histórico-cultural

Diferentes abordagens

Terapia cognitivo-comportamental

Esquizoanálise

Gestalt

Psicoterapia breve

Psicologia Humanista

Legislação (formação)

Não definido

Palavras-chave de indexação*

Estágio (clínico, Psicologia Social, profissionalizante, supervisionado)

Supervisão

Psicologia (escolar, hospitalar, jurídica, social, breve)

Formação de psicólogos

Aprendizagem

Formação do orientador profissional

Universidade

Arte; ciência; clínica psicanalítica; competência profissional; ensino; entrevista; experiência de estágio; experimentação; extensão universitária em orientação profissional; fenomenologia existencial; ferramentas de intervenção; formação acadêmica do psicólogo; formação clínica; formação profissional; gestalt-terapia; graduação; holding; modos de subjetivação; percepção de competência em tcc; produção escrita; psicanálise; saber; supervisão acadêmica; supervisão clínica; supervisão de terapia; suporte afetivo e técnico; terapeutas iniciantes; terapia cognitivo-comportamental; trabalho em grupo; violência

* Neste grupo foi considerado número maior de ocorrência, pois cada texto apresentou mais de uma palavra-chave em sua indexação.

Fonte: Dados da pesquisa. 
Nota-se que a eficiência na recuperação de um artigo científico em bases de dados tem relação estreita com essa questão. Por isso, uma maneira de uniformizar e garantir mais visibilidade aos estudos é adotar a terminologia em Psicologia proposta pela biblioteca BVS-Psi. Esta propõe o uso do termo "supervisão prática" quando há referências ao estudo sobre a prática de supervisão de estudantes envolvidos na aplicação prática de conteúdos apreendidos. Outra possibilidade nessa direção seria o uso do termo "supervisão acadêmica", consagrado pela literatura da área.

Sobre os temas abordados pelos artigos revisados, alguns resultados coincidem com o objetivo e a questão de busca deste estudo. Os textos exploraram reflexões sobre a experiência como supervisoras clínicas (Sei \& Paiva, 2011), o ponto de vista do supervisor acadêmico (Sá, Azevedo Júnior, \& Leite, 2010), relatos de experiência na supervisão de estágio (Guedes, 2006), análises de registros de docente supervisor (Silva, 1999), análise sobre a supervisão como elemento do tripé da formação do psicólogo (Peres, 1998) e uma investigação sobre o perfil de formação e atuação do supervisor de Estágio em Psicologia Clínica (Campos, 1995).

Cabe destacar um estudo que objetivou refletir sobre a supervisão de estágio, questionando os próprios objetivos dessa prática e as relações estabelecidas como naturais quando do desenvolvimento dessa atividade nos últimos anos de formação do psicólogo (Dias, 1998). Outros estudos partiram da experiência de supervisores para analisar questões dos estágios ou dos comportamentos dos estagiários nesse momento da formação (Pinheiro \& Darriba, 2010), bem como as vivências nos estágios (Barletta, Delabrida, \& Fonsêca, 2011).

O principal interesse dos estudos centra-se na formação e qualificação do psicólogo em perspectivas variadas de atuação. $\mathrm{O}$ mapeamento do cenário mostra a supervisão acadêmica entendida como instrumento essencial para desenvolver as competências do psicólogo à medida que abre espaço à discussão sobre o saber psicológico ou o saber-fazer na Psicologia; isto é, põe em questão o ensino e sua sistematização em foco. Explicita-se o entrelaçamento da teoria com a prática, marcado pelo encontro entre estagiário e supervisor como o sentido final desse momento do aprendizado (Barletta et al., 2012; Guedes, 2006; Sakamoto, 2006; Sei \& Paiva, 2011; Silva, 1999; Soares, 2009).

A supervisão acadêmica não é aula nem terapia: é ensino. Mais que isso, é afetada por posicionamentos subjetivos presentes na formação do estagiário e do supervisor. Do ponto de vista institucional, é um espaço de orientação teórico-metodológica para discutir a prática profissional no contexto acadêmico. Daí o tom marcadamente institucional dessa prática (Silva, 2006). É o lugar do saber e do sujeito na universidade, dispositivo essencial na formação do psicólogo frente às questões que o exercício profissional apresenta (Pinheiro \& Darriba, 2010).

Em termos práticos, nesse momento da formação do psicólogo, são apresentados e discutidos princípios que sustentam as práticas psicológicas em áreas diferentes, em instituições e no contato com demandas distintas (Guedes, 2006; Silva, 2006). Nessa direção, a análise dos dados se voltou à relação entre a supervisão acadêmica - elemento essencial dos cursos de graduação para a construção da identidade profissional dos estudantes - e o fazer profissional do psicólogo (Barletta et al., 2012; Dias, 1998).

A discussão corrente à luz dessas definições indica que a supervisão não pode se limitar ao ensino de técnicas nem incentivar a reprodução de certos fazeres. Esse momento da formação é propício para promover a reflexão sobre as técnicas empregadas em Psicologia, de modo a tanto enfatizar a indissociabilidade entre prática e teoria quanto auxiliar o estagiário na construção de seu percurso profissional (Silva et al., 2004).

A supervisão acadêmica pode assumir formatos variados, mas, em geral, tem objetivos e rotinas estabelecidas pelas instituições e acompanham o funcionamento 
dos estágios curriculares. É comum as supervisões acadêmicas serem semanais e terem carga horária equivalente ao tempo de prática dos estagiários (Silva, 1999). São momentos organizados para facilitar o planejamento das intervenções, dos atendimentos e das ações realizadas pelos estudantes; além de estimular a troca reflexiva de aspectos da ciência psicológica entre superior e estagiários (Melo-Silva, 2003; Soares, 2009).

Das experiências e configurações de supervisão encontradas nos artigos revisados, um modelo de supervisão propiciou ressignificar a experiência empírica do estágio e a elaboração de registros escritos cada vez mais reflexivos e críticos da prática e da formação. A proposta dos supervisores era trabalhar nos grupos de supervisão com casos redigidos pelos estudantes que eram compartilhados. O material era analisado em busca de ideias e estratégias para conduzir novas abordagens nos estágios (Maraschin, D'Agord, Santos \& Sordi, 2006).

Com esse mesmo desenho, outro estudo privilegiou a escrita das experiências de estágio, considerando que esse exercício estimula a construção de uma posição autoral até do processo de formação e da identidade profissional. A supervisão funcionava como outro campo de experimentação, em que a leitura do material produzido estimulava a produção de novas ações e maneiras de atuar (Diehl, Maraschin \& Tittoni, 2006).

Dois modelos de supervisão encontrados com foco na promoção do crescimento pessoal e técnico apresentavam a estruturação das supervisões que eram conduzidas conforme a abordagem clínica em questão (Barletta et al., 2011; Tavora, 2002). Nessa abordagem, a aprendizagem compartilhada nas supervisões devia ser orientada conforme o manejo clínico a que se referia, e cada estagiário era promotor de seu crescimento e do crescimento dos demais (Tavora, 2002). Esse formato também favoreceu a possibilidade de a relação do supervisor acadêmico com o estagiário ser mais colaborativa e bidirecional, além de favorecer a diversidade de métodos de ensino (Barletta et al., 2011). Tais ideias convergem para as de outros estudos revisados.

Nas experiências abarcadas por esta revisão, a fala de um estagiário sobre situações vividas no exercício profissional durante a formação marcou o contexto da supervisão. Nessa faceta da formação, o estudante tem de ser capaz de pensar sobre aspectos individuais, coletivos e sociais do fenômeno psicológico, bem como sobre as questões sociais que o atravessam. Mais que isso, tem de refletir acerca de sua condição de cidadão que se insere na realidade (na sociedade, na história, na cultura) das pessoas atendidas nos estágios (Silva, 2006; Soares, 2009).

No bojo desses pontos, aparecem a figura do supervisor e seu papel no processo de formação do psicólogo. Segundo os estudos, ele é uma figura central para qualificar o estudante e tem de ser modelo para o estagiário, de tal modo que a relação entre essas partes ajude o estudante a construir sua identidade profissional e definir repertórios para a atuação (Barletta et al., 2012). Também precisa ser um profissional capaz de manejar as angústias, os sofrimentos e as relações entre os estagiários, as práticas psicológicas, o momento da formação e as instituições e pessoas que os acolhem (Sei \& Paiva, 2011). Enfim, deve ter formação teórica e experiências na profissão, assim como habilidades de grupo e condução de equipes (Oliveira et al., 1970).

Entendido como protagonista responsável por agenciar o processo de inserção do estagiário no mercado de trabalho após a graduação, o supervisor acumula exigências por desenvolver nos estagiários o encantamento por determinadas áreas, conservando neles a possibilidade de criar e recriar práticas que são entendidas como consolidadas (Pinheiro \& Darriba, 2010; Soares, 2009). Na relação estabelecida no cenário da supervisão acadêmica, o supervisor tem a oportunidade de mostrar aos estudantes modos de atuação (envolvendo 
pensamentos, emoções, dúvidas etc.) do psicólogo em suas possibilidades variadas de inserção profissional (Silva et al., 2004).

Na dinâmica da supervisão, o supervisor se mostra como aquele que procura levar o estagiário a descobrir, por si, as respostas para os eventuais problemas que se impuserem durante o trabalho como psicólogo (Oliveira et al., 1970). O supervisor é um mediador no processo formativo, pois aponta aspectos básicos da atuação profissional como manejos técnicos, elementos éticos e o esforço por sempre se respaldar em fundamentos teóricos consolidados e cientificamente reconhecidos (Silva, 2004).

Destaca-se que o papel do supervisor acadêmico na formação em Psicologia - e na supervisão - tem sido problematizado e entendido segundo lógicas de abertura para o estranhamento e a possibilidade de não se saber tudo da teoria nem da prática de estágio em questão. Supervisor e supervisão precisam incentivar a reflexão sobre saberes e práticas, mas sem objetivar a resolver o problema da identidade profissional dos estudantes, e sim sustentando condições para que as categorias que compõem a vida e o trabalho sejam consideradas quando se parte para o exercício da Psicologia na sociedade contemporânea (Sá et al., 2010).

Fica claro que o processo de aprendizagem circunscrito à supervisão não pode ser entendido conforme lógicas tradicionais; por exemplo, como detentor do saber - professor/supervisor/psicólogo - que ensina a quem não sabe - o estudante que aprende (Sei \& Paiva, 2011). Isso explicita uma concepção de que ambos estão em troca e formação, rompendo com a ideia de que há um ponto de vista superior ocupado pela figura do supervisor (Sá et al., 2010). Existem momentos em que o supervisor acadêmico se vê ensinando algo para o estudante; noutros ele aprende; noutros mais, vê-se construindo algo com o estudante (Sakamoto, 2006). Nessa lógica de ressignificação e reconhecimento, urge pensar na supervisão e no papel do supervisor como elementos mais dispostos a problematizar os sentidos que realizam (Dias, 1998). Dadas as complexidades desse tipo de exercício profissional (supervisionar o outro), para qualificar e formar psicólogos, a supervisão tem de ser conduzida por um profissional com experiência prática e conhecimento teórico-científico sólido. Tais quesitos são essenciais para ajudar a superar dificuldades na qualificação do supervisor, a exemplo do desconhecimento de abordagens e das possíveis práticas psicológicas implementáveis em dada realidades ou em certas instituições (Barletta et al., 2012; Silva Neto, 2014).

No conjunto, os dados mostram que, quando se avaliam os supervisores, identifica-se um despreparo para o exercício da supervisão acadêmica. Isso se traduz em dificuldades para sistematizar e planejar as ações, bem como em limitações na produção científica sobre essa etapa da formação do psicólogo (Campos, 1995). Mais: numa avaliação crítica, essa necessidade presente de olhares para a formação em Psicologia mesmo 50 anos após a regulamentação da profissão se justifica por causa de concepções que não veem o espaço de formação (cursos, estágios e supervisão acadêmica) como objeto de pesquisas e investigações.

Com raras exceções, o supervisor acadêmico de estudantes de Psicologia, em geral com boa formação docente, não aprendeu a supervisionar; por isso, dele se exigem flexibilidade e disposição para refletir sobre sua prática e redefinir a supervisão quando necessário. Essa função ainda pressupõe muitas responsabilidades e exigências de formação que se materializam no encontro entre supervisor e estagiário (Barletta et al., 2012; Campos, 1995; Pinheiro \& Darriba, 2010).

No que se refere à regulamentação da atividade de supervisão (Costa Júnior \& Holanda, 1996), alguns aspectos são discutidos desde meados da década de 1990, quando se buscava, dentro do Sistema Conselhos de Psicologia, a regulamentação da prática da supervisão e a elaboração de critérios para contratação dos psicólogos supervisores. Conceituado como espaço 
que supervisiona as experiências dos estagiários para proporcionar o desenvolvimento profissional do psicólogo, o trabalho de supervisão é orientado para o favorecimento da aprendizagem de práticas e técnicas psicológicas, além de servir à formação ética e política de atitudes e hábitos profissionais (Costa Júnior \& Holanda, 1996).

Como se pode deduzir, ainda hoje há lacunas sobre esses pontos de regulamentação. Daí que se questiona: como ocorre a definição de supervisores? Como chegam a ocupar essa função nas instituições de ensino? Quais competências possuem?

Como essas questões não apareceram explicitamente nos estudos revisados, merecem ser aprofundadas em outras pesquisas. Além disso, nota-se que continua latente - como em 1970 - a construção de saberes sobre o perfil dos supervisores acadêmicos da formação em Psicologia - a exemplo da identificação das áreas centrais de atuação, das formações pós-ensino superior e da dinâmica nos espaços diversos de supervisão do país. Mesmo no contexto de expansão da oferta dos cursos de psicologia da década de 1970, já era grave a situação da supervisão de estágio (Oliveira et al., 1970). Isso parece ter se concretizado nos dias de hoje, em que o crescimento das ofertas de graduação na área não equivale a uma preocupação maior com questões estruturais de manutenção dos cursos, sobretudo com as condições de trabalho dos professores e supervisores acadêmicos.

Na situação de estágio na formação em Psicologia, muitas questões se entrelaçam: fatores institucionais, a experiência dos estagiários, a supervisão em si e a formação do supervisor. Por isso, às reflexões sobre o papel da supervisão na formação do psicólogo e como espaço de trabalho do psicólogo na condição de supervisor cabe abordar não só essas variáveis, mas também outras como as questões trabalhistas e institucionais que podem atravessar, qualitativamente, o momento da supervisão (Sakamoto, 2006; Silva Neto, 2014).

A experiência da supervisão acadêmica das práticas psicológicas mostra que, para a formação do psicólogo, o aprender está vinculado à integração de saberes e práticas acumulados histórica, cultural e socialmente. Nesse sentido, os grupos de supervisão devem permitir que o supervisor acadêmico vá se constituindo como tal, colaborando para o desenvolvimento do estudante num processo dialético de ensino e aprendizagem, ao mesmo tempo em que problematiza a inserção do estagiário e da Psicologia na sociedade contemporânea. O exercício da supervisão tem de ser o de propor estratégias que transformem o futuro psicólogo em um problematizador de sua prática e da realidade. A supervisão só pode ser pensada como processo e como análise de questões institucionais, teórico-práticas e existenciais (Dias, 1998). As discussões aqui apresentadas frisam isso. Se a supervisão assume uma configuração para o "ensino prático reflexivo" que possibilita a reflexão sobre a ação dos estagiários (Silva et al., 2004), então convém que a reflexão sobre a prática da supervisão de estágio seja tomada como procedimento fundamental para que o supervisor possa melhorar sua prática de ensino das competências de uma práxis demasiadamente complexa (Barletta et al., 2011).

Verificou-se que a ênfase nos estudos revisados recai na formação em Psicologia, retratando a questão dos estágios como momento-chave da formação acadêmica; mas é frágil a problematização do supervisor e da própria prática de supervisão nesse processo. Os dados sumarizados apontam um foco nos estudantes e nas perspectivas que influenciaram o desenvolvimento e a construção da identidade profissional. De fato, a literatura dá mostras de que surgem outras concepções de práticas de supervisão, mas ainda há muito a caminhar nessa direção, principalmente para amadurecer as reflexões, responder criticamente às demandas da formação do 
psicólogo brasileiro e ampliar a divulgação científica desse tipo de abordagem. Os artigos sinalizam essas carências ponderando que a literatura tem estudos escassos sobre métodos de supervisão, o que indica uma dificuldade em socializar as práticas de sucesso ou de fracasso que poderiam contribuir para a atividade de supervisão de outros profissionais (Barletta et al., 2012; Sei \& Paiva, 2011).

Constata-se que há uma necessidade ampla de instituir fóruns de discussões e construir agendas de pesquisa sobre a supervisão acadêmica em Psicologia, dadas as demandas do cotidiano e da sociedade contemporânea, na qual os psicólogos desenvolvem suas atividades (Peres, 1998). Embora alguns dos artigos apresentem pontos importantes sobre a atuação e a experiência dos supervisores, as reflexões ficam circunscritas ao campo das práticas dos estagiários. Não foram identificadas iniciativas de discutir a prática docente do supervisor. Esse tipo de reflexão, fomentada no contexto da própria universidade, pode contribuir para construir outras formas e delinear outros interesses - plurais e coletivos - para intervenção da Psicologia/dos psicólogos na realidade das pessoas, dos grupos e das comunidades. Na educação, essa atividade é amplamente estimulada, pois se entende que o professor reflexivo coloca sua rotina de trabalho em constante investigação para construir e mobilizar respostas às questões pedagógicas e àquelas concernentes ao processo de ensino e aprendizagem (Pimenta \& Anastasiou, 2010).

As ideias expressas pelos artigos lidos e analisados para esta revisão sugerem que a questão maior a ser destacada é o enquadramento da situação de supervisão, tanto quanto a demanda por reflexões dos psicólogos/professores/supervisores que a desenvolvem. Permeiam esse momento da formação questões relacionadas com as instituições de ensino superior, com o processo de ensino e aprendizagem (e suas diferentes concepções) e com a responsabilidade de preparar o estudante para o exercício profissional à luz da prática de estágio e das discussões dela decorrentes e presentes na supervisão acadêmica.

\section{Considerações finais}

Essa revisão oferece compreensões das práticas de supervisão acadêmica divulgadas na literatura científica e relativas à formação do psicólogo brasileiro. As práticas abordadas pelos estudos revisados indicam que a supervisão é um momento-chave para o exercício da prática profissional no âmbito da graduação porque contribui para aprendizagem de teorias e técnicas aplicadas nas várias áreas da Psicologia. Também estimula a definição de posturas profissionais e a construção da identidade profissional - seja de estudantes, seja de supervisores - alicerçada na formação teórica, prática e ética.

Embora este estudo ofereça uma reflexão sobre aspectos importantes para problematizar a supervisão e o papel do supervisor acadêmico na formação dos psicólogos, ele padece de duas limitações. Primeiramente, a opção por selecionar estudos brasileiros considerando as características da formação do psicólogo no Brasil e suas peculiaridades; essa opção impede comparações e a compreensão de como a supervisão acadêmica ocorre em outros contextos socioculturais. Saber disso seria útil para o avanço científico e a proposição de discussões e ações no cenário nacional. Em segundo lugar, a limitação se refere à prevalência de estudos sobre experiências ou que tivessem delineamento teórico. É importante divulgar as experiências nos cursos, mas as evidências científicas podem ser avaliadas com mais análise, mais precisão e mais aprofundamento quando originárias de pesquisas com rigor metodológico e com um desenho que permitam generalizar a abordagem do problema investigado e o tratamento dado aos resultados apresentados.

Todavia, essas limitações, dentre outras, não anulam os esforços empreendidos neste estudo de revisão inovador; 
tampouco fragilizam a constatação de que a supervisão acadêmica de estágios em Psicologia é fundamental para a formação do estudante. Por isso, requer construções teóricas e práticas sobre seus mecanismos, seus modos e suas expressões nas realidades institucionais do país. Pesquisas que abordem os espaços de supervisão acadêmica e busquem compreender as trajetórias e a formação dos supervisores são bem-vindas para enriquecer e qualificar a formação do psicólogo, considerando-se as vicissitudes e complexidades que permeiam esse processo. 
Referências
Andrade, A. (2005). O estágio supervisionado e a práxis docente. In M. L. S. F. SILVA (Org.), Estágio curricular: contribuições para o redimensionamento de sua Prática. (2a ed). Natal, RN: Editora da UFRN.

Assis, R. L. M., \& Rosado, I. V. M. (2012). A unidade teoria-prática e o papel da supervisão de estágio nessa construção. Revista Katálysis, 15(2), 203-211.

Barletta, J. B., Delabrida, Z. N. C., \& Fonsêca, A. L. B. (2011). Conhecimento, habilidades e atitude em TCC: percepção de terapeutas iniciantes. Revista Brasileira de Terapias Cognitivas, 7(1), 21-9.

Barletta, J. B., Fonsêca, A. L. B., \& Delabrida, Z. N. C. (2012). A importância da supervisão de estágio clínicoparaodesenvolvimentodecompetências em terapia cognitivo-comportamental. Psicologia: Teoria e Prática, 14(3), 153-67.

Campos, L. F. L. (1995). Investigando a formação e atuação do supervisor de estágio em Psicologia Clínica. Estudos de Psicologia (Campinas), 12(3), 7-29.

Costa Júnior, A. L., \& Holanda, A. F. (1996). Estágio em psicologia: discussão de exigências e critérios para o exercício de supervisor de estágio. Psicologia: Ciência e Profissão, 16(2), 4-9.

Delvan, J.S., Ramos, M. C., \& Dias, M. B. (2002)A psicologia escolar/educacional na Educação Infantil: o relato de uma experiência com pais e educadoras. Psicologia: Teoria e prática, 4(1), 49-60.

Dias, R. M. S. (1998). Dos encontros em supervisão: devenires na formação de psicólogos. Temas em Psicologia, 6(1), 21-9.

Diehl, R., Maraschin, C., \& Tittoni, J. (2006). Ferramentas para uma psicologia social. Psicologia em Estudo, 11(2), 407-15.

Emílio, S.A., Mataresi, A., Horvat, C., \& Figueiredo, P. (2012). Reflexões sobre a experiência de um grupo de estágio em psicologia escolar. In R. Molina, \& C. B. Angelucci (Org.). Interfaces entre psicologia e educação: desafios para a formação do psicólogo (pp. 125-133). São Paulo, SP: Casa do Psicólogo.

Guedes, C. R. (2006). A supervisão de estágio em psicologia hospitalar no curso de graduação: relato de uma experiência. Psicologia: Ciência e Profissão, 26(3), 516-23.

Maraschin, C., D'Agord, M. R. L., Santos, N. I. S., \& Sordi, R. O. (2006). A escrita do caso e a ressignificação da experiência de estágio. Aletheia, 24, 35-47.

Melo-Silva, L. L. (2003). Formação do psicólogo: a contribuição da orientação profissional. Psicologia, 4(1), 42-53.

Oliveira, A.F., Chermont, J. M. A., Glycério, L. M. I. M., César, S. C.; Albuquerque, T. L., \& Caldas, Y. (1970). O estágio supervisionado: estudo preliminar. Arquivos Brasileiros de Psicologia, 22(2), 47-53.

Peres, W. S. (1998). A instituição do estágio: uma reflexão sobre os analisadores. Psicologia em Estudo, 3(2), 163-76.

Pimenta, S. G., \& Anastasiou, L. G. C. (2010). Docência no ensino superior (4a ed.). São Paulo, SP: Cortez.

Pinheiro, N. N. B., \&Darriba, V.A. (2010).Aclínica psicanalítica na universidade: reflexões a partir do trabalho de supervisão. Psicologia Clínica, 22(2), 45-55.

Sá, R. N., Azevedo Junior, O., \& Leite, T. L. (2010). Reflexões fenomenológicas sobre a experiência de estágio e supervisão clínica em um serviço de psicologia aplicada universitário. Revista da Abordagem Gestáltica, 16(2), 135-40.

Sakamoto, C. K. (2006). Foco e estratégia da supervisão clínica em psicoterapia breve. Cadernos de Psicopedagogia, 6(10).

Sei, M. B., \& Paiva, M. L. S. C. (2011). Grupo de supervisão em psicologia e a função de holding do supervisor. Psicologia Ensino \& Formação, 2(1), 9-20.

Silva, L. L. M. (1999). Estágio profissionalizante em orientação profissional: experiência de supervisão em um curso de psicologia. Revista da ABOP, 3(1), 119-35.

Silva, P. R. M. (2006). A supervisão em psicologia jurídica: a violência em questão. Psicologia para América Latina, (8). Recuperado em 12 de dezembro de 2014, de http:// pepsic.bvsalud.org/scielo.php?script $=$ sci_ arttext\&pid=S1870-350X2006000400007 
Silva, S. M. C. (2004). Algumas reflexões sobre a arte e a formação do psicólogo. Psicologia: Ciência e Profissão, 24(4), 100-11.

Silva, S. M. C., Ribeiro, M. J., \& Marçal, V. P. B. (2004). Entrevistas em psicologia escolar: reflexões sobre o ensino e a prática. Psicologia Escolar e Educacional, 8(1), 85-90.

Silva Neto, W. M. F. (2014). Supervisão de estágio em psicologia escolar: contribuições da psicologia crítica à formação e prática do supervisor. Tese de Doutorado não publicada, Pontifícia Universidade Católica de Campinas, SP.

Soares, L. L. M. (2009). A Gestalt-terapia na universidade: da f(ô)rma à boa forma. Estudos e Pesquisas em Psicologia, 9(1), 152-63.

Tavora, M. T. (2002). Um modelo de supervisão clínica na formação do estudante de psicologia: a experiência da UFC. Psicologia em Estudo, 7(1), 121-30.

Ulup, L., \& Barbosa, R. B. (2012). A formação profissional e a ressignificação do papel do psicólogo no cenário escolar: uma proposta de atuação de estagiários a psicólogos escolares. Psicologia: Ciência e Profissão, 32(1), 250-63.

Zaslavsky, J., Nunes, M. L. T., \& Eizirik, C. L. (2003). A supervisão psicanalítica: revisão e uma proposta de sistematização. Revista de Psiquiatria do Rio Grande do Sul, 25(2), 297-309. 


\section{Walter Mariano de Faria Silva Neto}

Docente da Universidade Federal do Triângulo Mineiro, Uberaba - MG. Brasil.

E-mail: walterfarianeto@gmail.com

\section{Wanderlei Abadio de Oliveira}

Universidade de São Paulo, Ribeirão Preto - SP. Brasil.

E-mail:wanderleio@usp.com

\section{Endereço para correspondência}

Universidade Federal Do Triângulo Mineiro. Curso de Psicologia.

Rua Getúlio Guaritá, 159.

Bairro Abadia. CEP 38025-180. Uberaba - MG. Brasil.

Recebido: 11/12/2014, Aprovado: 03/11/2015. 